\title{
Lipid accelerating the fibril of islet amyloid polypeptide aggravated the pancreatic islet injury in vitro and in vivo
}

\author{
Xiao-Dan Mo ${ }^{1}$, Li-Ping Gao ${ }^{3}$, Qing-Jun Wang ${ }^{3}$, Jie Yin ${ }^{1}$ and Yu-Hong Jing ${ }^{1,2^{*}}$
}

\begin{abstract}
Background: The fibrillation of islet amyloid polypeptide (IAPP) triggered the amyloid deposition, then enhanced the loss of the pancreatic islet mass. However, it is not clear what factor is the determinant in development of the fibril formation. The aim of this study is to investigate the effects of lipid on IAPP fibril and its injury on pancreatic islet.

Methods: The fibril form of human IAPP (hIAPP) was tested using thioflavin-T fluorescence assay and transmission electron microscope technology after incubated with palmitate for $5 \mathrm{~h}$ at $25^{\circ} \mathrm{C}$. The cytotoxicity of fibril hIAPP was evaluated in INS-1 cells through analyzing the leakage of cell membrane and cell apoptosis. Type 2 diabetes mellitus (T2DM) animal model was induced with low dose streptozotocin combined the high-fat diet feeding for two months in rats. Plasma biochemistry parameters were measured before sacrificed. Pancreatic islet was isolated to evaluate their function.
\end{abstract}

Results: The results showed that co-incubation of hIAPP and palmitate induced more fibril form. Fibril hIAPP induced cell lesions including cell membrane leakage and cell apoptosis accompanied insulin mRNA decrease in INS-1 cell lines. In vivo, Plasma glucose, triglyceride, rIAPP and insulin increased in T2DM rats compared with the control group. In addition, IAPP and insulin mRNA increased in pancreatic islet of T2DM rats. Furthermore, T2DM induced the reduction of insulin receptor expression and cleaved caspase-3 overexpression in pancreatic islet.

Conclusions: Results in vivo and in vitro suggested that lipid and IAPP plays a synergistic effect on pancreatic islet cell damage, which implicated in enhancing the IAPP expression and accelerating the fibril formation of IAPP.

Keywords: IAPP, Lipid, Pancreatic islet, T2DM, Insulin, Palmitate

\section{Background}

Type 2 diabetes (T2DM) is characterized by the hyperlipidemia and aberrant metabolism. Aberrant metabolism caused the serials of symptoms in diabetic patients including overweight or obesity, unbalance of anabolism and catabolism in adipocyte, chronic inflammation which induced the insulin resistance. Amyloid deposition consisted of islet amyloid polypeptide (IAPP) can be observed in pancreatic biopsy of patient with T2DM. IAPP is a 37-amino acid peptide of the calcitonin gene family. It is the most abundant component of pancreatic

\footnotetext{
* Correspondence: jingyh@|zu.edu.cn

'Institute of Anatomy and Histology \& Embryology, Neuroscience, School of Basic Medical Sciences, Lanzhou University, No. 199 of Donggang West Road, Lanzhou City, Gansu Province 730000, People's Republic of China

${ }^{2}$ Key Laboratory of Preclinical Study for New Drugs of Gansu province, Lanzhou University, No. 199 of Donggang West Road, Lanzhou City, Gansu Province 730000, People's Republic of China

Full list of author information is available at the end of the article
}

amyloid $[1,2]$. IAPP has been suggested to be toxic to $\beta$ cells and to be involved in the development of T2DM [3, 4]. It has been proposed that overexpression of IAPP contributes to pancreatic amyloid formation and development of T2DM, this viewpoint supported by transgenic mouse and rat studies involving the overexpression of human IAPP (hIAPP) in islets of Langerhans [5]. Clinical studies indicate that hIAPP preferentially forms the amyloid deposition that implicates the pathology of islet hyalinization which is the pathological characteristic of T2DM [6-8]. Amyloid deposition is observed not only in patients with T2DM but also in some overweight or non-diabetic individuals [9-11]. Therefore, evidence suggests that some unidentified factors are involved in the regulation of IAPP secretion and amyloid deposition. Several studies have reported that the high expression of IAPP can be induced by lipid condition [4, 12-14]. It is 
known to cause the typical characteristic of T2DM [15, 16]. But how and what accelerating amyloid deposition by lipid is not clear.

Amyloid deposition is initiated by changed of protein conformation. Especially, the fibril form is preference to accumulate, which damage the cell membrane and induced the cell apoptosis [17-21]. The aim of the present study is to explore the effects of lipid on fibril formation of IAPP and the toxicity of fibril IAPP on pancreatic islet cells. The T2DM animal model was established by feeding with high fat diet or streptozotocin (STZ) injection, the IAPP levels and the pancreatic islet pathology and function were investigated. High dose STZ badly impairs the insulin secretion by inducing $\beta$-cell death mimicking type 1 diabetes. Low-dose STZ has been known to induce a mild impairment of insulin secretion which is similar to the feature of the later stage of type 2 diabetes $[22,23]$. The investigators have been developed a rat model by feeding the animal with high-fat diet following low-dose STZ that closely mimic the metabolic characteristics of human type 2 diabetes [24].

\section{Methods}

Reagents

The hIAPP was synthesized using $t$-boc chemistry and purified by reverse phase high-performance liquid chromatography (Shanghai Zi Yu Biotech Co. Ltd., Shanghai, China). 1,1,1,3,3,3-Hexafluoro-2-propanol (HFIP), palmitate (PA), thioflavin-T (ThT) and STZ were purchased from Sigma (St. Louis, MO, USA). Enzymatic diagnostic kits for plasma glucose and triglyceride were purchased from Randox (Crumlin Co., Antrim, UK). The lactate dehydrogenase (LDH) assay kit and TUNEL kit were purchased from Roche (Roche, USA). The sandwich enzymelinked immunosorbent assay (ELISA) kits of insulin and rIAPP were obtained from R\&D (R\&D, IL, USA). The anti-IAPP, and IR $\beta$ antibodies were purchased from Abcam (Cambridge, UK). Anti-Cleaved caspase3 antibody was purchased from Cell signaling (Cell signaling Technology, MA, USA). The anti-glyceraldehyde 3-phosphate dehydrogenase (GAPDH) antibody was obtained from Santa Cruz (Santa Cruz, CA, USA). The RPMI-1640 medium and the fetal bovine serum (FBS) were purchased from Gibco BRL (Gaithersburg, MD, USA). The water used in all experiments was ultrapure, and supplied by a Milli-Q water purification system from Millipore.

\section{ThT fluorescence assays}

ThT based fluorescence assays were performed to evaluate the hIAPP fibril form. Briefly, hIAPP was first dissolved in HFIP and sonicated for 2 min to homogenize the sample. hIAPP was then diluted in $25 \mathrm{mM}$ PBS (pH 7.4) containing $50 \mathrm{mM} \mathrm{NaCl}$ and $1 \%$ HFIP to a final concentration of $20 \mu \mathrm{M}$. The hIAPP were co-incubated with $200 \mu \mathrm{M}$ PA at $25{ }^{\circ} \mathrm{C}$ for $5 \mathrm{~h}$. Samples were aliquoted at designated time intervals and ThT based fluorescence assays were used to detect the fibril formation of hIAPP; the fluorescence emission experiments were performed on a Hitachi FL-2700 fluorometer (Toyko, Japan) with the excitation and emission wavelengths set at 450 and $482 \mathrm{~nm}$, respectively. All experiments were repeated for at least three times.

\section{Transmission electron microscopy (TEM)}

$20 \mu \mathrm{M}$ hIAPP were co-incubated with $200 \mu \mathrm{M}$ PA at $25^{\circ}$ $\mathrm{C}$ for $5 \mathrm{~h}$, then Five microliters of samples to be imaged were spotted on a 300 mesh Formvar-carbon coated copper grid (Shanghai, China) and stained with $1 \%$ freshly prepared uranyl formate. Samples were air dried and observed under a JEM2100 TEM (JEMO, Toyko, Japan) operating at an accelerating voltage of $100 \mathrm{kV}$.

\section{Cell culture and treatment}

The rat insulinoma cell line (INS-1) was purchased from the Institute of Biochemistry and Cell Biology of Shanghai. The cells were briefly maintained in an RPMI-1640 medium supplemented with 10\% FBS, $2 \mathrm{mmol} / \mathrm{L} \mathrm{L-glu-}$ tamine, $1 \mathrm{mmol} / \mathrm{L}$ sodium pyruvate, $10 \mathrm{mmol} / \mathrm{L}$ HEPES, $50 \mathrm{mmol} / \mathrm{L}$ mercaptoethanol, $100 \mathrm{U} / \mathrm{mL}$ penicillin, and $100 \mathrm{U} / \mathrm{mL}$ streptomycin at $37^{\circ} \mathrm{C}$ in a humid atmosphere (95\% relative humidity, $5 \% \mathrm{CO} 2$ ). For the peptide treatment, lyophilized hIAPP was dissolved in HFIP, which was removed by evaporation under N2. The hIAPP incubation with palmitate for $5 \mathrm{~h}$ at $25^{\circ} \mathrm{C}$, then used to treat cells. INS-1 cells were incubated with $20 \mu \mathrm{M}$ and $50 \mu \mathrm{M}$ fibril hIAPP for $24 \mathrm{~h}$ to evaluate the LDH leakage, levels of insulin mRNA and apoptosis.

\section{LDH assay}

The LDH release indicates the change of membrane permeability, which can reflect the damage extent of the cell membrane. The cells were precipitated by centrifugation $(1500 \times \mathrm{g})$ for $10 \mathrm{~min}$ at room temperature at the end of the treatments. The supernatants were transferred to a 96-well plate. The LDH activity was assayed using the cytotoxicity detection kit according to the manufacturer's instructions. The cells treated with $1 \%$ Triton X-100 were used as high control, while media without cells served as a low control. The results were expressed as \% LDH leakage [(experimental value - low control) / (high control - low control) $\times 100]$ [25].

\section{Animals and treatment}

A total of 48 healthy male Sprague Dawley (SD) rats weighing 200-220 g were purchased from the Experimental Animal Center of Lanzhou University. The animals were housed in a standard environment at $20-25^{\circ} \mathrm{C}$ and $50-70 \%$ humidity and maintained under a $12 \mathrm{~h}$ light-dark cycle with food and water ad libitum. All animal experimental protocols 
were approved by the institutional Animal Ethics Committee, Lanzhou University (permission number: SCXK Gan 2009-0004). The animals were randomly divided into four groups as follows: control group (single injection with equal volume of $0.1 \mathrm{M}$ citrate buffer through peritonea, feeding with regular diet), STZ group (single injection with STZ through peritonea, $30 \mathrm{mg} / \mathrm{kg}$, STZ dissolved in $0.1 \mathrm{M}$ citrate buffer, feeding with regular diet), HD group (single injection with equal volume of $0.1 \mathrm{M}$ citrate buffer through peritonea, feeding with high-fat diet), and STZ + HD group (single injection with STZ through peritonea, $30 \mathrm{mg} / \mathrm{kg}$, STZ dissolved in $0.1 \mathrm{M}$ citrate buffer, feeding with regular diet). Diets (Ke Ao Co. Ltd., Beijing) contained 15\% (low fat) or $36 \%$ (high fat) calories derived from fat. Fat was provided as corn oil and hydrogenated coconut oil, with the ratio of saturated to unsaturated fatty acids being 1:3 in each diet. The progressively increasing amounts of fat were balanced by decreasing amounts of carbohydrate $(65 \mathrm{kcal} \%$ and $44 \mathrm{kcal} \%$ in low- and high-fat diets, respectively) and constant amounts of protein (20 kcal\%).

\section{Examination of plasma rIAPP, insulin, triglyceride and glucose in diabetic rats}

Plasma was isolated by low-speed centrifugation of blood at $4{ }^{\circ} \mathrm{C}$. The plasma glucose and triglyceride were measured with respective enzymatic diagnostic kits according to the manual instruction. Plasma insulin and rIAPP were measured by respective ELISA kit according to the manual instruction. All data were obtained from two independent measurements, each with triplicate incubations.

\section{Glucose tolerance test (GTT) and insulin sensitivity tests (IST)}

For the glucose tolerance and insulin sensitivity tests, the rats were intraperitoneally injected with glucose ( $2 \mathrm{~g} / \mathrm{kg}$ ) or subcutaneously injected with human regular insulin (0.75 unit/ $\mathrm{kg}$ ) after $12 \mathrm{~h}$ of fasting, respectively. Blood samples were collected from the tail vein at $0 \mathrm{~min}, 30 \mathrm{~min}, 60 \mathrm{~min}, 90 \mathrm{~min}$, and $120 \mathrm{~min}$ after treatment. The blood glucose levels were measured.

\section{Histology examination of pancreatic islet}

After two months, four rats, which were randomly selected from each group, were anesthetized. The pancreatic tail was isolated (in a size of $0.5 \times 0.5 \times 0.5 \mathrm{~cm}$ ) and performed on formalin-fixed. The paraffin-embedded pancreas specimens were cut at a $5 \mu \mathrm{m}$ thickness. Sections were collected and stained by hematoxylin-Eosin (H-E) to evaluate the histopathological changes of pancreatic islet. To identify the pancreatic islet, sections were stained with insulin antibody (1:100) overnight at $4{ }^{\circ} \mathrm{C}$. Then the sections were rinsed with $0.01 \mathrm{M}$ PBS and incubated with FITC-IgG (1:50). The sections were observed under fluorescence microscope and scanned in dark field. The other sections were used to incubate using the rIAPP primary antibody (1:100), overnight at $4{ }^{\circ} \mathrm{C}$. The sections were rinsed with $0.01 \mathrm{M}$ PBS and incubated with the corresponding second antibodies at $37{ }^{\circ} \mathrm{C}$ for $1 \mathrm{~h}$, then rinsed and incubated with streptavidinconjugated horseradish peroxidase $(1: 100)$ at $37{ }^{\circ} \mathrm{C}$ for $1 \mathrm{~h}$. The immunoreactivity was visualized with $0.05 \%$ a diaminobenzidine (DAB) as a chromogen. The sections were observed under a microscope and scanned in bright field. The pancreatic islets were manually outlined. The pancreatic islet area was calculated using ImageJ software. The optical density was used to quantify the rIAPP expressed by normalized with unit area of pancreatic islet.

\section{TUNEL assay}

The paraffin-embedded pancreas specimens were cut at a $5 \mu \mathrm{m}$ thickness. And terminal deoxynucleotidyl transferasemediated deoxyuridine triphosphate biotin nick end labeling (TUNEL) assay was performed on the sections. Sections were treated with $0.2 \% \mathrm{H}_{2} \mathrm{O}_{2}$ for $10 \mathrm{~min}$, rinsed in $0.1 \mathrm{M}$ PBS, and incubated with Proteinase K Solution (contain $200 \mathrm{mmol}$ Tris, $\mathrm{pH}, 7.4,0.5 \mathrm{mmol}$ EDTA, and proteinase $\mathrm{K}$ $1 \mathrm{mg} / \mathrm{ml}$ ) for $20 \mathrm{~min}$ at room temperature. Then the sections were incubated in TUNEL reaction mixture using the In Situ Cell Death Detection Kit for $1 \mathrm{~h}$ at $37{ }^{\circ} \mathrm{C}$, then rinsed in $0.1 \mathrm{M}$ PBS three times for $5 \mathrm{~min}$ and incubated in Converter peroxidase (POD) for $30 \mathrm{~min}$ at $37{ }^{\circ} \mathrm{C}$, rinsed in $0.1 \mathrm{M}$ PBS three times for $5 \mathrm{~min}$, and color-developed with SIGMA FAST, a DAB POD substrate. The pancreatic islets were manually outlined. The TUNEL positive cells were counted and normalized with unit area of pancreatic islet.

\section{Procedure of pancreatic islet isolation}

After two months, eight rats, which were randomly selected from each group, were anesthetized. And the pancreas was isolated. After enzymatic digestion of the pancreas, islets of Langerhans were purified using a discontinuous density gradient of ficoll solutions as previously reported [26], with minor adjustments. Briefly, the common bile duct was cannulated and $1 \mathrm{ml}$ of digestion solution $(0.2 \mathrm{mg} / \mathrm{ml}$ collagenase in HBSS containing $10 \mathrm{mmol}$ HEPES) was injected to distend the pancreas. The pancreas was removed and placed for $15 \mathrm{~min}$ at $37^{\circ} \mathrm{C}$ in a Petri dish filled with $5 \mathrm{ml}$ of digestion solution to isolate the islet.

\section{RNA extraction and Q-RT-PCR}

The total RNA was extracted from the isolated pancreatic islet or INS-1 cells using the RNAiso plus reagent (Takara Biotech, Co., Ltd., Dalian, China) and depleted of contaminating DNA with RNase-free DNase according to the manufacturers' instructions. CDNA was synthesized from $1 \mu \mathrm{g}$ of RNA with M-MuLV reverse transcriptase and random hexamer according to the manufacturer's instructions (Fermentas, Burlington, Canada). Q-RT-PCR was performed using 
the PIKoREAl96 detector (Thermo Scientific, USA). The primers for the rIAPP were 5'-GCCCACTGAAAGGGATCTTG-3 (forward) and 5'-GCACTTCCGTTTGTCCACCT-3' (reverse). The primers for the rat preproinsulin were: 5' -CAGCACCTTTGTGGTTCTCACTT-3' (forward) and 5'-CTCCACCCAGCTCCAGTTGT-3' (reverse). The rat GAPDH primers were 5'-GGCACAGTCAAGGCTGAGAATG-3' (forward) and 5'-ATGGTGGTGAAGACGCCAGTA-3' (reverse). The assays were initiated for $5 \mathrm{~min}$ at $95{ }^{\circ} \mathrm{C}$ and 40 cycles of $15 \mathrm{~s}$ at $94{ }^{\circ} \mathrm{C}$ and $1 \mathrm{~min}$ at $60{ }^{\circ} \mathrm{C}$. The relative levels of amylin or preproinsulin mRNA expression were calculated using the $2^{\Delta \mathrm{CT}}$ method.

\section{Protein extraction and western blot analysis}

The total proteins were extracted from pancreatic islet or INS-1 cells using RIPA buffer that contains protease inhibitors. The proteins $(50 \mu \mathrm{g})$ were fractionated on $10 \%$ sodium dodecyl sulfate polyacrylamide gel electrophoresis, and then transferred into polyvinylidene fluoride membranes. The membranes were blotted with anti-IR $\beta$ (1:1000), anticaspase-3 (1:1000), and anti-GAPDH (1:5000) antibodies, as well as with horseradish peroxidase-conjugated second antibody (1:5000). The immunoreactive protein bands were visualized by enhanced chemiluminescence.

\section{Statistical analysis}

The data were expressed as mean \pm SEM. Statistical analysis was performed using SPSS statistical program at 17.0version. The difference between two groups was analyzed by Student's $t$-test, whereas that among three or more groups was analyzed by one-way or two way analysis of variance with least significant difference test. The difference with $P<0.05$ was considered statistically significant.

\section{Results}

\section{Effects of lipid on fibrillation of hIAPP}

Twenty $\mu \mathrm{M}$ hIAPP incubated with $200 \mu \mathrm{M}$ palmitate at $25^{\circ} \mathrm{C}$, and then ThT-based fluorescence assays were performed. hIAPP exhibited maximum ThT emission with a long lag time of $4.3 \pm 0.6 \mathrm{~h}$ (Fig. 1a) compared with palmitate treated-hIAPP $(1.5 \pm 0.2 \mathrm{~h}$, Fig. 1a). This result suggested palmitate accelerated the formation of fibril hIAPP. Under TEM, a mesh of typical long linear fibrils was detected for palmitate treated-hIAPP incubated for $5 \mathrm{~h}$ (Fig. 1c). In contrast, only a few linear fibrils together with significant amount of amorphous aggregates were observed in untreated hIAPP (Fig. 1b), which is consistent with the results by ThT assay.

\section{Effects of fibril hIAPP on membrane permeability of pancreatic cells}

The INS-1 cell, which was the cell line of insulinoma characterized by insulin secretion were incubated with exogenous fibril hIAPP for $24 \mathrm{~h}$ at concentrations of
$20 \mu \mathrm{M}$ and $50 \mu \mathrm{M}$ to further confirm the direct effect on the INS-1 cells. The results showed that the insulin mRNA levels decreased about $50 \%$ after treatment with fibril hIAPP (Fig. 2a). These findings also suggested that fibril hIAPP may repress the transcription of insulin gene. Membrane permeability was evaluated with the ratio of the LDH leakage. As shown in Fig. 2b, the LDH leakage increased to 6-8 folds after incubation with fibril hIAPP. This result suggested that hIAPP aggravated the cell damage in a dose-dependent manner. In addition, the hIAPP treatment induced the caspase- 3 high expression, which indicated the initiation of DNA damage and cell apoptosis (Fig. 2c and d).

\section{Changes of body weight, GTT and IST in diabetic rats}

As shown in Fig. 3b, the body weight gain in high-fat diet group is more than in the control. Alternatively, body weight gain in STZ treated group is less than in the control. And the extent of body weight gain in STZ + HD group is similar as the control. The glucose tolerance increased about one fold and the insulin sensitivity decreased about $20 \%$ in the HD and HD + STZ groups, respectively, compared with that in the control group (Fig. 3c and d).

\section{Changes of plasma rIAPP, insulin, triglyceride and glucose in diabetic rats}

As shown in Fig. 4a, Plasma glucose was higher in the STZ (about $250 \mathrm{mg} / \mathrm{dl}$ ) and STZ + HD (about $220 \mathrm{mg} / \mathrm{dl}$ ) groups than that in the control group after two months of treatment. Among them, plasma glucose increased significantly in the STZ group. Plasma triglyceride was higher in the HD (about $70 \mathrm{mg} / \mathrm{dl}$ ) and STZ + HD (about $60 \mathrm{mg} / \mathrm{dl}$ ) groups than that in the control group. Among them, plasma triglyceride significantly increased in the HD group (Fig. 4b). The plasma insulin decreased in STZ group, and increased in $\mathrm{HD}$ and $\mathrm{HD}+\mathrm{STZ}$ group compared with the control group (Fig. 4c). Plasma rIAPP significantly increased in HD + STZ group compared with the control group $(p<0.01$, Fig. 4d). Also, rIAPP increased in STZ and HD groups compared with the control group ( $p<0.05$, Fig. $4 d$ ).

\section{Changes of pancreatic islet pathology in diabetic rats}

To confirm the pancreatic islet morphology and exclude the inflammation which induced by STZ injection, we observed the pancreatic islet by $\mathrm{H}$-E staining under microscope. As shown in Fig. 5a, the boundary is obvious between islet and acinus. We did not find inflammatory cell infiltration in islet. To prove islet function, the insulin expression in islet was detected by immunofluorescence. Results showed insulin immunoreaction is positive in islet from control, HD, STZ and STZ + HD groups (Fig. 5b). The rIAPP in the islet were evaluated using immunohistochemistry and semi-quantitative methods. As shown in Fig. $5 \mathrm{c}$ and $\mathrm{d}$, the rIAPP expression increased in the islet of the 

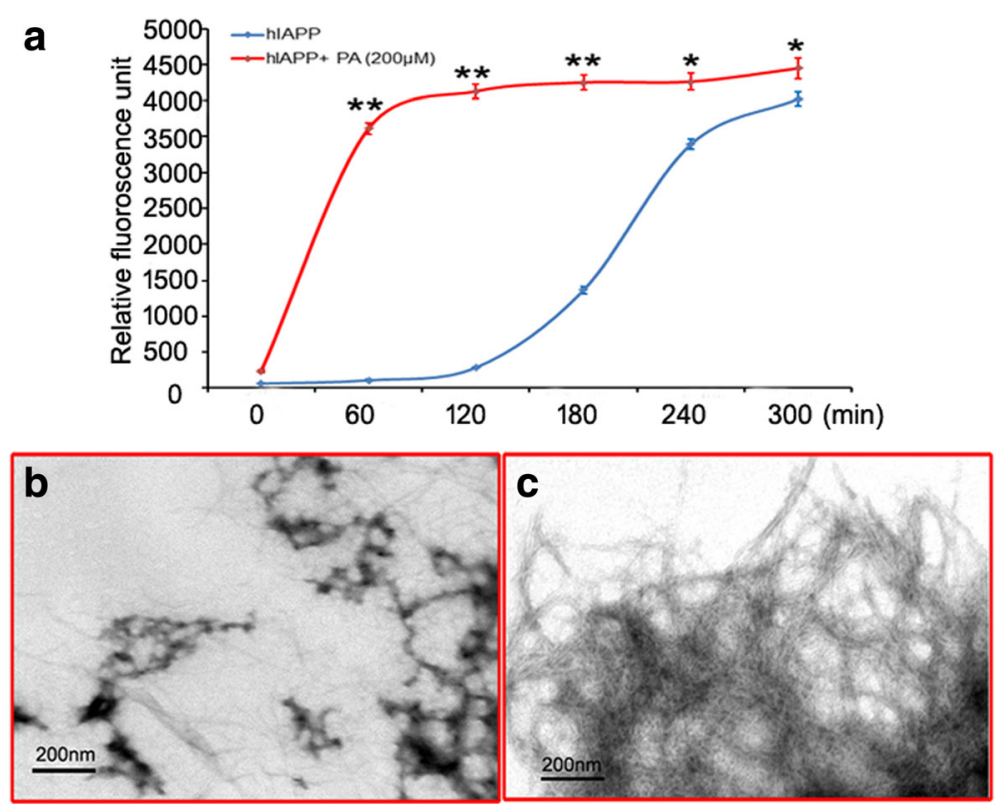

Fig. 1 Effects of palmitate on the fibrillation of hIAPP. a Relative thioflavin-T fluorescence intensity. b TEM image of hIAPP alone. c TEM image of hIAPP co-incubated with palmitate. ${ }^{*}$ denotes $p<0.05$ and ${ }^{* *}$ denotes $P<0.01$ compared to the hIAPP. $n=3$. One-way ANOVA was used with post hoc test

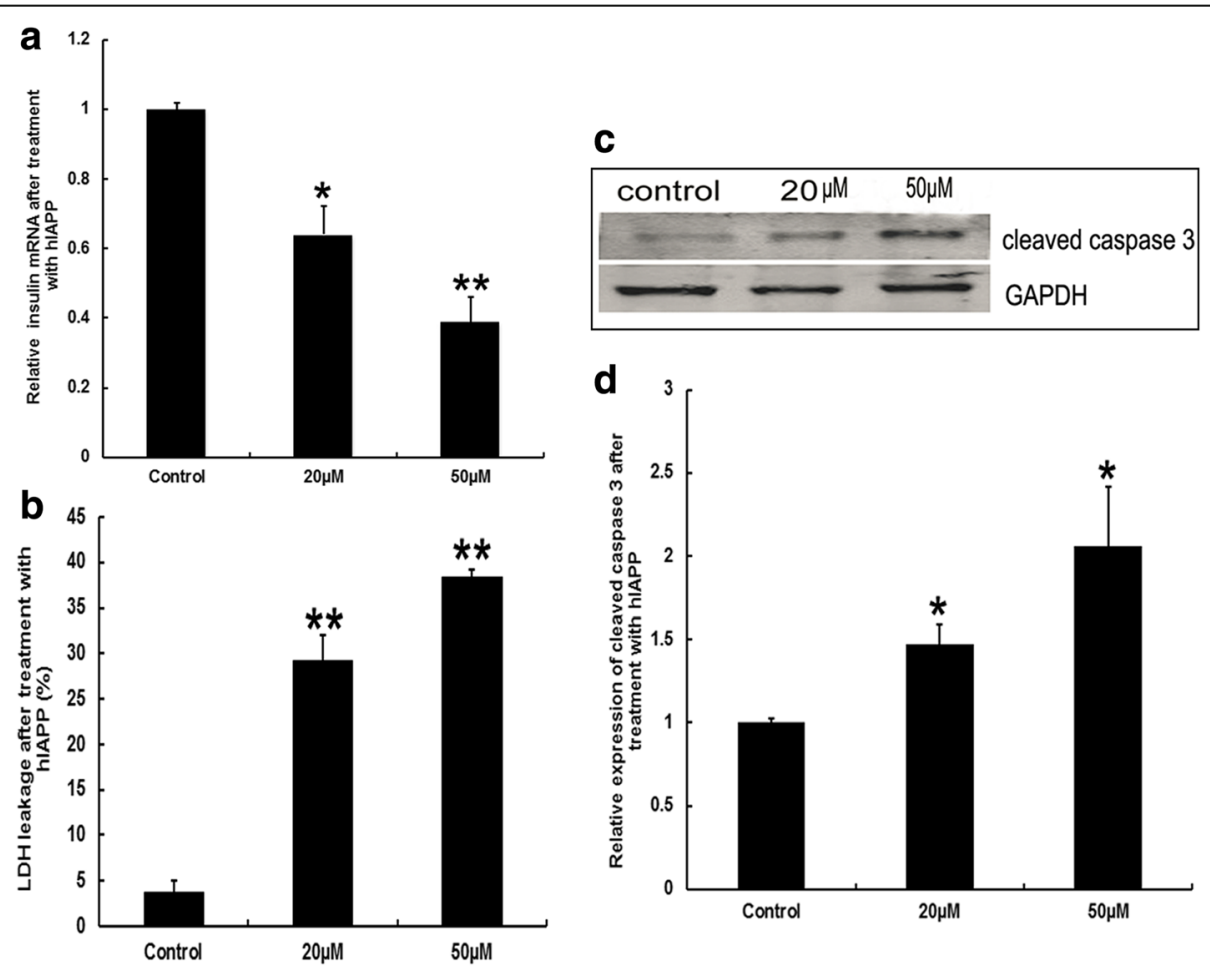

Fig. 2 Effects of fibril hIAPP on INS-1 cells. a mRNA levels of insulin. b Membrane permeability evaluated by LDH leakage assay. c Representative images of WB for cleaved aspase-3 expression. $\mathbf{d}$ Relative quantitation of cleaved caspase-3 expression was performed. ${ }^{*}$ denotes $p<0.05$ and ${ }^{* *}$ denotes $P<0.01$ compared to the control group. $n=3$. One-way ANOVA was used with post hoc test 

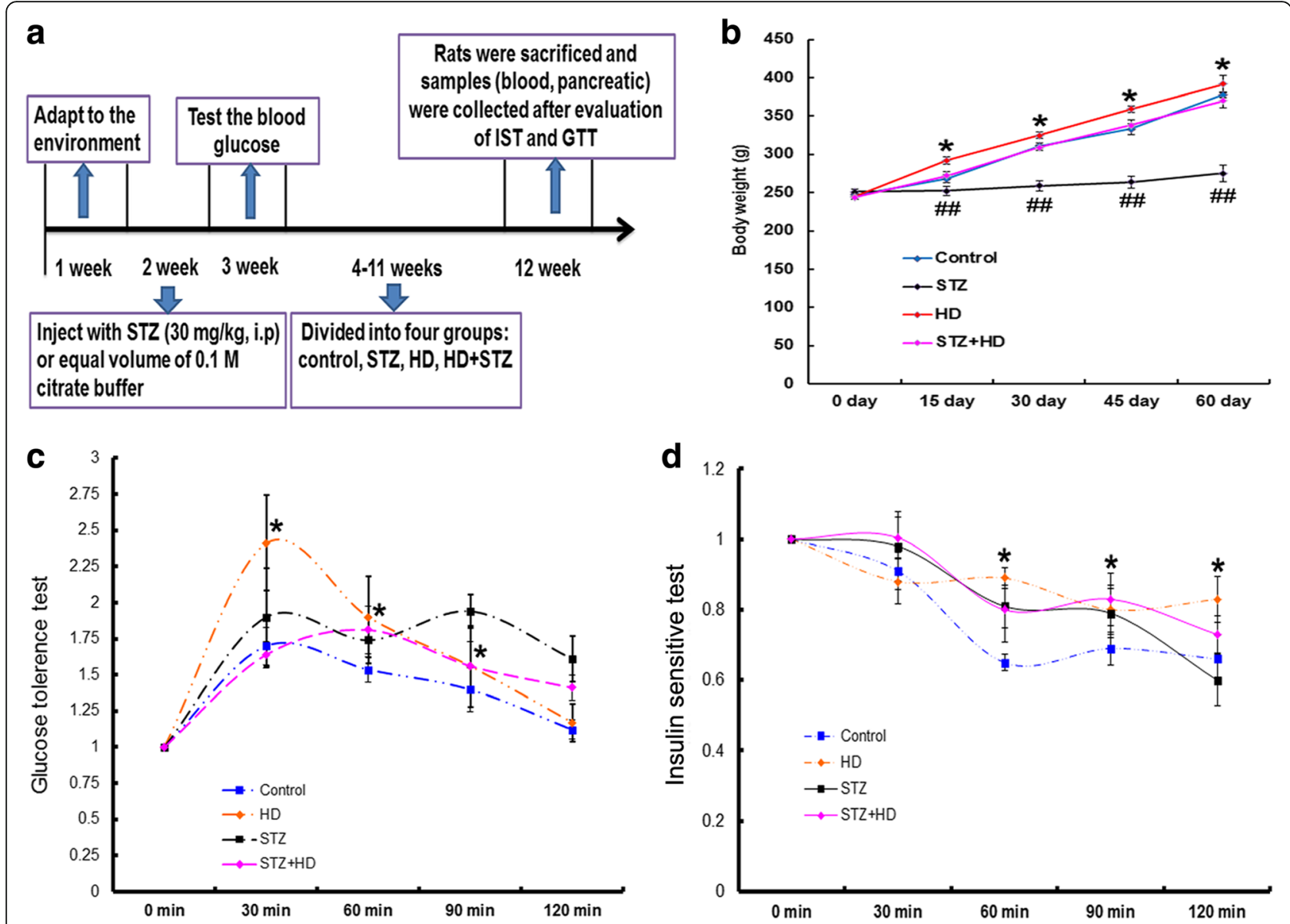

Fig. 3 Body weight, fast glucose tolerance and insulin sensitivity after treating with high-fat diet, STZ injection, and STZ injection combined with high-fat diet. a Flow chart of animal experiment. $\mathbf{b}$ The extent of body weight gain duration of two months. ${ }^{*}$ denotes $p<0.05$ in the HD group vs. control group; \#\# denotes $p<0.01$ in the STZ group vs. control group. $n=12$. c Glucose tolerance is evaluated after $12 \mathrm{~h}$ fasting. ${ }^{*}$ denotes $p<0.05$ in the HD group vs. control group, $\mathrm{n}=12$. $\mathbf{d}$ Insulin sensitivity was evaluated after $12 \mathrm{~h}$ fasting, ${ }^{*}$ denotes $p<0.05$ in the HD group vs. control group. $\mathrm{n}=12$. Two-way ANOVA was used with post hoc test

$\mathrm{HD}$ and HD + STZ groups compared with the control group. No significant difference was found in the STZ group compared with the control group. To evaluate the cell apoptosis, we detected the number of TUNEL positive cells in islet. As shown in Fig. 5e and f, numbers of TUNEL positive cell increased in the HD, STZ, and HD + STZ groups compared with the control group.

\section{Effects of HD on isolated pancreatic islet}

To quantify the rIAPP expression in pancreatic islet, the islet was isolated from pancreas. The rIAPP mRNA increased in HD and STZ + HD groups compared with the control, but no difference in STZ group (Fig. 6a). Similarly, the insulin mRNA in HD and STZ + HD groups, but not STZ group increased compared with the control (Fig. 6b). Total protein was extracted from isolated pancreatic islet, and the levels of IR- $\beta$ and caspase- 3 were measured by western blot. The results showed IR- $\beta$ expression decreased in $\mathrm{HD}$ and $\mathrm{STZ}+\mathrm{HD}$ groups compared with the control (Fig. 6c and d). Additionally, the caspase- 3 increased in STZ, HD and STZ + HD groups compared with the control (Fig. 6e and f).

\section{Discussion}

Amyloid deposition plays a critical role in many different human diseases, including Huntington's disease, Parkinson's disease (PD), Alzheimer's disease (AD) and T2DM. Among these diseases, T2DM together with AD are leading causes of morbidity and mortality in the elderly. Both diseases share common clinical and biochemical features [27], including functional tissue loss due to accumulation and aggregation of small peptides, such as IAPP in the pancreas of T2DM patients, or beta amyloid in AD patients. Specifically, IAPP fibrils arise following initial increased production of IAPP which leads to oligomeric aggregation of IAPP molecules that then assemble into amyloid fibrils in pancreatic islets, eventually resulting in pancreatic beta cell loss [28-30]. More secretion of IAPP 

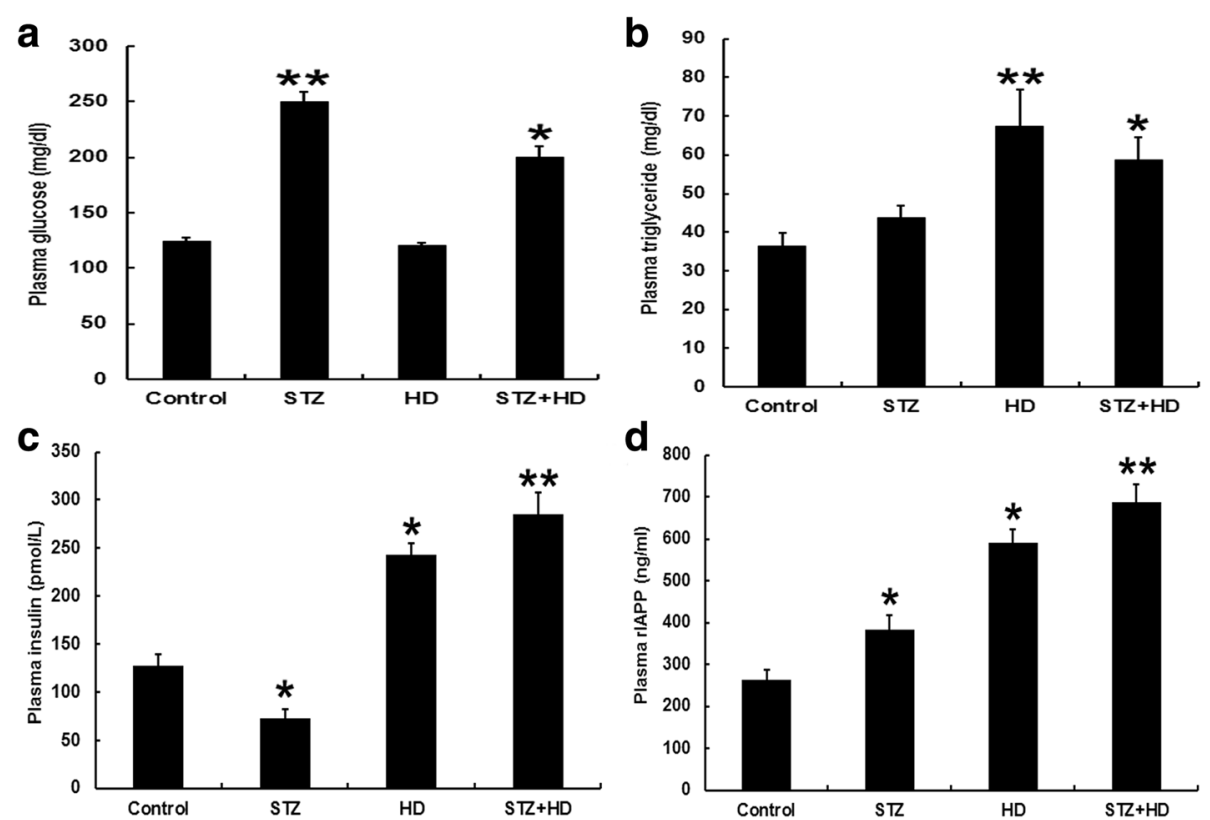

Fig. 4 Blood biochemical parameters of rats after treating with high-fat diet, STZ injection, and STZ injection combined with high-fat diet for 2 months. a Plasma glucose. b Plasma triglyceride. c Plasma insulin. d Plasma rIAPP. * denotes $p<0.05$ compared with the control group; ** denotes $p<0.01$ compared with the control group. $\mathrm{n}=12$. Two-way ANOVA was used with post hoc test

is the precondition, but not the determinant factor in amyloid deposition. Increasing literatures have reported IAPP fibrils play the dramatic roles in the development of amyloid deposition. Therefore, facilitation of fibril formation accelerates the amyloid deposition. In our present study, we found incubation of hIAPP with palmitate increased the fibril form which caused the increase of membrane permeability and apoptosis in INS-1 cells. In type 2 diabetic rats induced by feeding with high fat diet, we fund rIAPP expression increased accompanied pancreatic islet cell apoptosis, but no typical amyloid deposition. In isolated pancreatic islet tissue, we fund rIAPP mRNA and insulin mRNA increased, but insulin receptor decreased in diabetic rats, which may implicate the abnormal insulin signals. Given the insulin signals play pivotal roles in cell survival, pancreatic cell apoptosis partially contributed to the reduction of insulin signaling.

IAPP is co-localized with insulin in the islet beta-cells and is co-secreted with insulin in response to beta-cell stimulation by both glucose and non-glucose secretagogues agents, such as arginine [31]. Therefore, therapies that alter endogenous insulin secretion are likely to cause parallel changes in IAPP secretion. Both insulin and IAPP gene expression and release by pancreatic islets are regulated by glucose [13, 32-34]. In vitro, the study showed that palmitate and oleate cause transcriptional induction of amylin gene in beta-cells and murine islets. This induction is mediated by the $\mathrm{Ca}^{2+}$-PKC signaling pathway and de novo synthesized proteins. However, the effect of lipid on the expression and release of IAPP by pancreatic islet in vivo is not clear. Our present studies indicate high fat diet combined with the low dose STZ injection induced the features of T2DM characterized by decrease of insulin sensitivity and increase of plasma insulin, glucose and triglyceride, as well plasma rIAPP augment and islet cell apoptosis. To confirm the changes of pancreatic islet under high fat diet consumption, pancreatic islet was isolated and its function was analyzed. These results suggested the transcription of insulin and amylin were affected under high fat diet condition. Together with all data in vivo, we think simultaneous changes of IAPP expression, glucolipid metabolism and insulin sensitivity caused islet cell apoptosis which contributed to the onset of T2DM.

The most widely accepted hypothesis is that IAPPinduced cytotoxicity occurs via a membrane disruption mechanism. The experimental evidence suggested that the peptide $A \beta$, involved in Alzheimer's disease, could form cation-selective channels in planar lipid bilayers [13]. Similar experiments showed that hIAPP could also form cationselective channels and ultimately disrupt the membranes [35]. These channels have been also observed for other amyloidogenic proteins suggesting that the toxicity of amyloid proteins seems to be linked to their shared potential to form pores in membrane [36, 37]. Many studies suggest hIAPP could induce membrane damage. But the exact mechanism of hIAPP-induced membrane disruption is far from clear. And numerous models have been described during recent years [38-41]. A report concluded that soluble oligomers from several types of amyloids, including hIAPP, specifically increase lipid bilayer conductance, while 

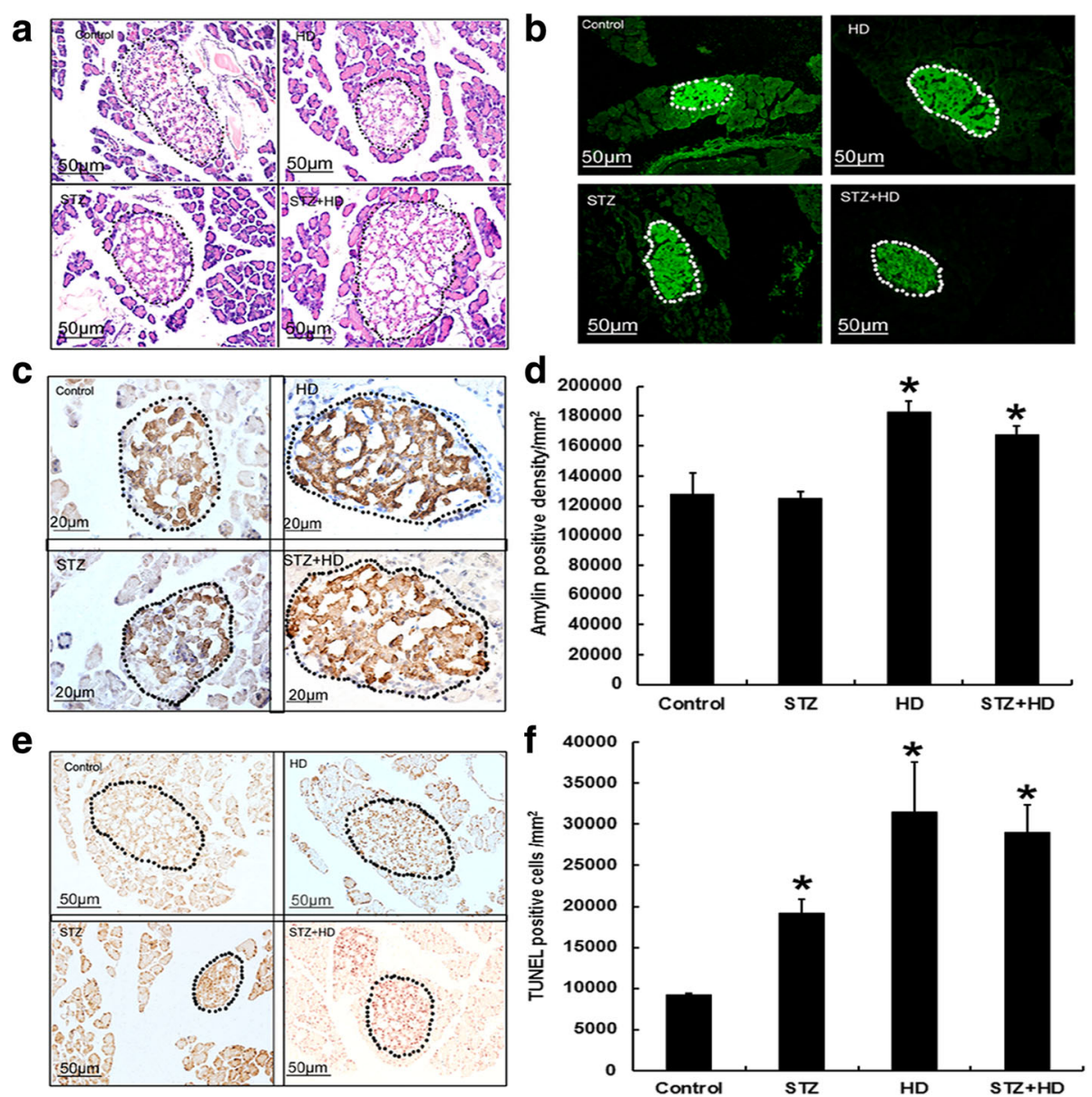

Fig. 5 Morphology of pancreatic islet after treatment with STZ injection, high-fat diet, and STZ injection combined with high-fat diet in rats. a Representative images of $\mathrm{H}-\mathrm{E}$ staining to show the islet by dashed lines. $\mathbf{b}$ Representative images of insulin immunoflurorescence staining to show the islet by dashed lines. c Representative images of amylin expression in the islet (outlined by dashed lines). $\mathbf{d}$ Levels of amylin expression calculated with ImageJ software in sixteen islets from four rats each group. e Representative images of TUNEL staining in the islet (outlined by dashed lines). $\mathbf{f}$ Numbers of TUNEL positive cells in the islet were calculated and normalized by unit area of pancreatic islet. ${ }^{*}$ denotes $p<0.05$ compared with the control group. $n=4$. Two-way ANOVA was used with post hoc test

the soluble low molecular weight species have no effect, suggesting that this may represent the common primary mechanism of pathogenesis in amyloid-related diseases, such as $\mathrm{AD}, \mathrm{PD}$ and diabetes [42].

The lipid condition accelerated the IAPP toxicity not only based on its high expression but also on the associated IAPP conformation. The dynamics and extent of IAPP oligomerization and aggregation were shown to be important parameters of IAPP toxicity [40, 43, 44]. However, the absence of the islet amyloid in several transgenic mouse strains with very high amylin production contradicted this suggestion. Therefore, additional factors need to be considered. The islet amyloid occurred after a persistent intake of a high-fat diet in transgenic mouse models [42, 45]. Finding the effects of lipid on IAPP toxicity was a critical issue. A previous study suggested that free fatty acids (FFAs) can act as direct potent stimulators of amylin fibrillogenesis [46]. Our study showed that insulin resistance and rIAPP production occurred in rats feeding with high-fat diet. These led to a chronic overproduction of rIAPP. Another study indicated that FFAs not only enhanced fibril formation from synthetic hIAPP in vitro, but also rapidly led to the appearance of an abnormal intragranular material in cells of cultivated hIAPP transgenic mouse islets [47-49].

Cell damage with IAPP was caused by the increase of membrane permeability. Accordingly, evidence showed that various sizes of the hIAPP-induced membrane pores or openings, ranging from $\mathrm{Ca}^{2+}$-permeable to permeable for fluorescent dyes with a size larger than $1 \mathrm{kDa}$ [5052]. Soluble hIAPP and amyloid oligomers generally could have characteristics of pore-forming protein toxins like $\alpha$-hemolysin, and might have a similar mechanism of action [53-55]. Our results also confirmed that cell membrane permeability increased after incubation with hIAPP in a dose-dependent manner. 

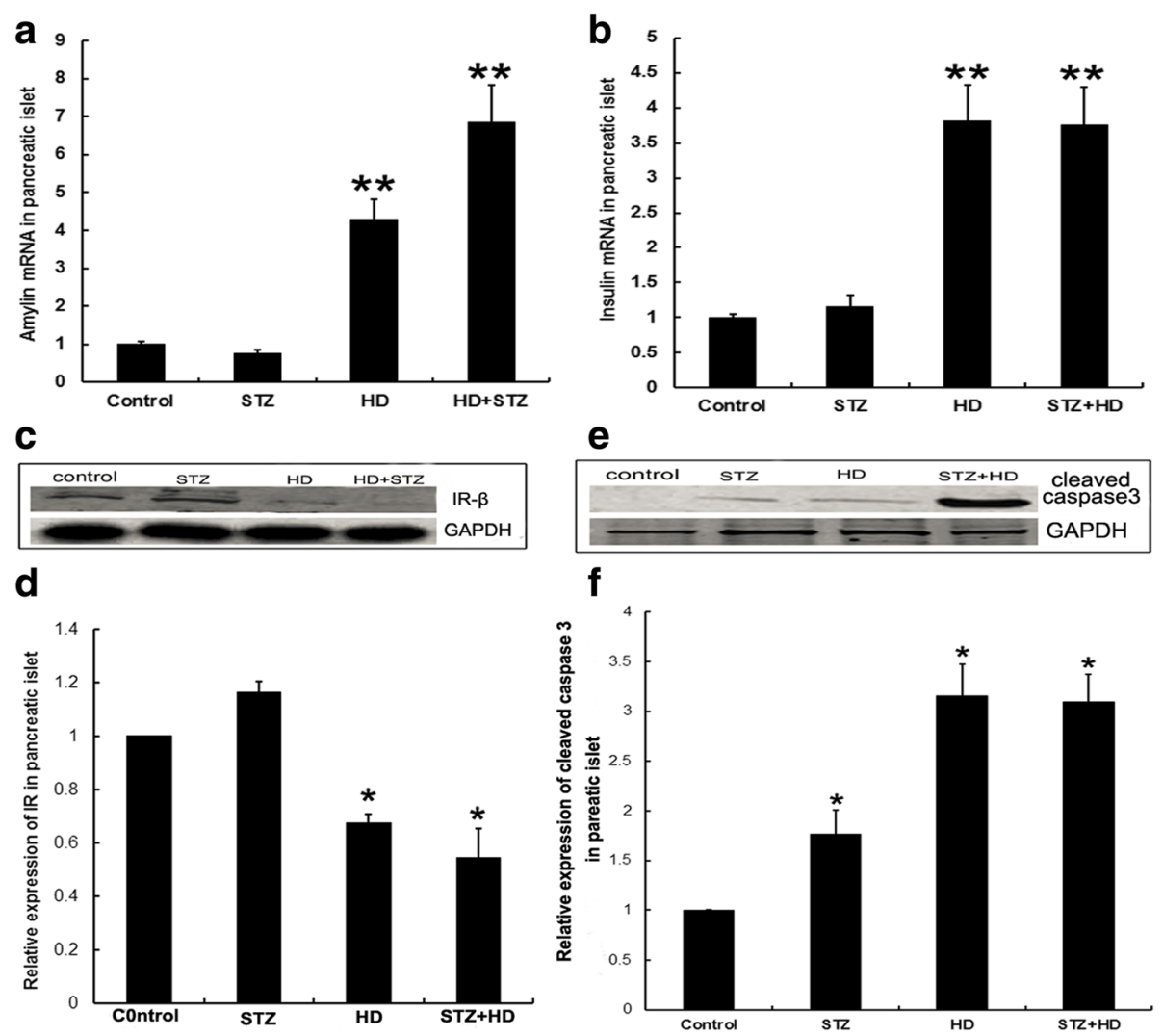

Fig. 6 Isolated pancreatic islet function was evaluated after treatment with STZ injection, high-fat diet, and STZ injection combined with high-fat diet in rats. a mRNA levels of amylin. $\mathbf{b}$ mRNA levels of insulin. $\mathbf{c}$ Representative images of WB for IR $\beta$ expression. Relative quantitation of IR $\beta$ expression was performed and shown in (d). e Representative images of WB for cleaved caspase-3 expression. $\mathbf{f}$ Relative quantitation of cleaved caspase-3 expression was performed. * denotes $p<0.05$ compared with the control group; ${ }^{* *}$ denotes $p<0.01$ compared with the control group. $n=4$. Two-way ANOVA was used with post hoc test

\section{Conclusions}

Fibril hIAPP directly damaged the pancreatic cells characterized by increase of permeability of cell membrane, inhibition of insulin secretion, and triggering cell apoptosis. Furthermore, high fat diet induced endogenous rIAPP secretion accompanied the insulin secretion, but in isolated pancreatic islet, high fat diet reduced the insulin receptor expression, suggesting the insulin signaling is inhibited. Insulin resistance and IAPP expression induced by fatty acids aggravated the pancreatic islet cell apoptosis in vivo. Together with evidence from in vivo and in vitro, suggested fatty acid and amylin plays the synergistic effect on pancreatic islet cell damage which involved in amylin high expression and fibril formation of IAPP, cell membrane leakage and cell apoptosis. Also, the limitation and deficiency in our experiment is nonblinded methods, which may produce the bias.

\section{Abbreviations}

aa: amino acid; DAB: Diaminobenzidine; FAs: Fatty acids; FBS: Fetal bovine serum; GAPDH: Glyceraldehyde 3-phosphate dehydrogenase; HD: High-fat diet; HFIP: 1,1,1,3,3,3-Hexafluoro-2-propanol; hIAPP: human islet amyloid polypeptide; LDH: The lactate dehydrogenase; MTT: thiazolyl blue tetrazolium bromide; PA: Palmitate; Q-RT-PCR: Quantitative real-time PCR; rIAPP: rodent islet amyloid polypeptide; STZ: Streptozotocin; T2DM: Type 2 diabetes mellitus; TEM: Transmission Electronic Microscopy; ThT: thioflavin-T

\section{Acknowledgments}

We would like to acknowledge Miss Bei Wang for help with Electronic Microscopy technology and Miss Xiao-Xia Xi and Miss Jing Sun for animal care and sample collection.

\section{Funding}

This work is partly supported by National Natural Science Foundation of China (No. 81370448 and 81570725) to Jing Yu Hong.

\section{Availability of data and materials}

The datasets used and/or analyzed during the current study are available from the corresponding author on reasonable request.

\section{Authors' contributions}

XDM and YHJ planned experiments, interpreted data, and approved the version to be published. XDM and YHJ performed most of the experiments and analyzed data and YHJ wrote the paper. QJW and JY participated in the animal experiment. LPG participated in acquisition of the study specimens. All authors read and approved the final paper.

\section{Ethics approval}

This animal study was approved by the institutional Animal Ethics Committee, Lanzhou University (permit number: SCXK Gan 2009-0004). 


\section{Consent for publication}

Not applicable

\section{Competing interests}

The authors declare that they have no competing interests.

\section{Publisher's Note}

Springer Nature remains neutral with regard to jurisdictional claims in published maps and institutional affiliations.

\section{Author details}

'Institute of Anatomy and Histology \& Embryology, Neuroscience, School of Basic Medical Sciences, Lanzhou University, No. 199 of Donggang West Road, Lanzhou City, Gansu Province 730000, People's Republic of China. ${ }^{2}$ Key Laboratory of Preclinical Study for New Drugs of Gansu province, Lanzhou University, No. 199 of Donggang West Road, Lanzhou City, Gansu Province 730000, People's Republic of China. ${ }^{3}$ Institute of Biochemistry and Molecular Biology, School of Basic Medical Sciences, Lanzhou University, No. 199 of Donggang West Road, Lanzhou City, Gansu Province 730000, People's Republic of China.

\section{Received: 3 January 2018 Accepted: 2 March 2018} Published online: 09 March 2018

\section{References}

1. Cooper GJ, Willis AC, Clark A, Turner RC, Sim RB, Reid KB. Purification and characterization of a peptide from amyloid-rich pancreases of type 2 diabetic patients. Proc Natl Acad Sci U S A. 1987;84:8628-32.

2. Westermark P, Wernstedt C, O'Brien TD, Hayden DW, Johnson KH. Islet amyloid in type 2 human diabetes mellitus and adult diabetic cats contains a novel putative polypeptide hormone. Am J Pathol. 1987;127:414-7.

3. Mukherjee A, Soto C. Prion-like protein aggregates and type 2 diabetes. Cold Spring Harb Perspect Med. 2017;7(5):a024315.

4. Hoppener JW, Jacobs HM, Wierup N, Sotthewes G, Sprong M, de Vos P, Berger $\mathrm{R}$, Sundler F, Ahren B. Human islet amyloid polypeptide transgenic mice: in vivo and ex vivo models for the role of hIAPP in type 2 diabetes mellitus. Exp Diabetes Res. 2008;2008:697035.

5. Matveyenko AV, Butler PC. Islet amyloid polypeptide (IAPP) transgenic rodents as models for type 2 diabetes. ILAR J. 2006;47:225-33.

6. Schneider HM, Storkel S, Will W. Amyloid of islets of Langerhans and its relation to diabetes mellitus (author's transl). Dtsch Med Wochenschr. 1980;105:1143-7.

7. Rocken C, Linke RP, Saeger W. Immunohistology of islet amyloid polypeptide in diabetes mellitus: semi-quantitative studies in a post-mortem series. Virchows Arch A Pathol Anat Histopathol. 1992:421:339-44.

8. Clark A, Wells CA, Buley ID, Cruickshank JK, Vanhegan RI, Matthews DR, Cooper GJ, Holman RR, Turner RC. Islet amyloid, increased A-cells, reduced B-cells and exocrine fibrosis: quantitative changes in the pancreas in type 2 diabetes. Diabetes Res. 1988:9:151-9.

9. Bell ET. Hyalinization of the islets of Langerhans in nondiabetic individuals. Am J Pathol. 1959;35:801-5.

10. Ehrlich JC, Ratner IM. Amyloidosis of the islets of Langerhans. A restudy of islet hyalin in diabetic and non-diabetic individuals. Am J Pathol. 1961;38:49-59.

11. Westermark P. Quantitative studies on amyloid in the islets of Langerhans. Ups J Med Sci. 1972;77:91-4.

12. Hull RL, Andrikopoulos S, Verchere CB, Vidal J, Wang F, Cnop M, Prigeon RL, Kahn SE. Increased dietary fat promotes islet amyloid formation and betacell secretory dysfunction in a transgenic mouse model of islet amyloid. Diabetes. 2003;52:372-9.

13. Meier DT, Morcos M, Samarasekera T, Zraika S, Hull RL, Kahn SE. Islet amyloid formation is an important determinant for inducing islet inflammation in high-fat-fed human IAPP transgenic mice. Diabetologia. 2014;57:1884-8

14. Ma Z, Westermark GT. Effects of free fatty acid on polymerization of islet amyloid polypeptide (IAPP) in vitro and on amyloid fibril formation in cultivated isolated islets of transgenic mice overexpressing human IAPP. Mol Med. 2002:8:863-8.

15. Jeong HR, An SS. Causative factors for formation of toxic islet amyloid polypeptide oligomer in type 2 diabetes mellitus. Clin Interv Aging. 2015;10:1873-9.

16. Xin A, Mizukami H, Inaba W, Yoshida T, Takeuchi YK, Yagihashi S. Pancreas atrophy and islet amyloid deposition in patients with elderly-onset type 2 diabetes. J Clin Endocrinol Metab. 2017;102:3162-71.
17. Han S, Kollmer M, Markx D, Claus S, Walther P, Fandrich M. Amyloid plaque structure and cell surface interactions of beta-amyloid fibrils revealed by electron tomography. Sci Rep. 2017;7:43577.

18. Oskarsson ME, Singh K, Wang J, Vlodavsky I, Li JP, Westermark GT. Heparan sulfate proteoglycans are important for islet amyloid formation and islet amyloid polypeptide-induced apoptosis. J Biol Chem. 2015;290:15121-32.

19. Guo SM, Bag N, Mishra A, Wohland T, Bathe M. Bayesian total internal reflection fluorescence correlation spectroscopy reveals hIAPP-induced plasma membrane domain organization in live cells. Biophys J. 2014;106:190-200.

20. Radovan D, Opitz N, Winter R. Fluorescence microscopy studies on islet amyloid polypeptide fibrillation at heterogeneous and cellular membrane interfaces and its inhibition by resveratrol. FEBS Lett. 2009;583:1439-45.

21. Misumi $Y$, Ueda M, Obayashi K, Jono H, Yamashita T, Ando Y. Interaction between amyloid fibril formation and extracellular matrix in the proceedings of VIIIth international symposium on familial Amyloidotic polyneuropathy. Amyloid. 2012;19(Suppl 1):8-10

22. Reed MJ, Meszaros K, Entes LJ, Claypool MD, Pinkett JG, Gadbois TM, Reaven GM. A new rat model of type 2 diabetes: the fat-fed, streptozotocin-treated rat. Metab Clin Exp. 2000:49:1390-4.

23. Srinivasan K, Viswanad B, Asrat L, Kaul CL, Ramarao P. Combination of highfat diet-fed and low-dose streptozotocin-treated rat: a model for type 2 diabetes and pharmacological screening. Pharmacol Res. 2005;52:313-20.

24. Sahin K, Onderci M, Tuzcu M, Ustundag B, Cikim G, Ozercan IH, Sriramoju V, Juturu V, Komorowski JR. Effect of chromium on carbohydrate and lipid metabolism in a rat model of type 2 diabetes mellitus: the fat-fed, streptozotocin-treated rat. Metab Clin Exp. 2007;56:1233-40.

25. Sutton R, Peters M, McShane P, Gray DW, Morris PJ. Isolation of rat pancreatic islets by ductal injection of collagenase. Transplantation. 1986:42:689-91.

26. Xu S, Kim JH, Hwang KH, Das R, Quan X, Nguyen TT, Kim SJ, Cha SK, Park KS. Autocrine insulin increases plasma membrane K(ATP) channel via PI3K-VAMP2 pathway in MIN6 cells. Biochem Biophys Res Commun. 2015;468:752-7.

27. Gotz J, Ittner LM, Lim YA. Common features between diabetes mellitus and Alzheimer's disease. Cell Mol Life Sci. 2009;66:1321-5.

28. Haataja L, Gurlo T, Huang CJ, Butler PC. Islet amyloid in type 2 diabetes, and the toxic oligomer hypothesis. Endocr Rev. 2008;29:303-16.

29. Konarkowska B, Aitken JF, Kistler J, Zhang S, Cooper GJ. The aggregation potential of human amylin determines its cytotoxicity towards islet betacells. FEBS J. 2006:273:3614-24.

30. Goldsbury C, Goldie K, Pellaud J, Seelig J, Frey P, Muller SA, Kistler J, Cooper GJ, Aebi U. Amyloid fibril formation from full-length and fragments of amylin. J Struct Biol. 2000;130:352-62.

31. Li X, Ma L, Zheng W, Chen T. Inhibition of islet amyloid polypeptide fibril formation by selenium-containing phycocyanin and prevention of beta cell apoptosis. Biomaterials. 2014;35:8596-604.

32. Verchere CB, D'Alessio DA, Prigeon RL, Hull RL, Kahn SE. The constitutive secretory pathway is a major route for islet amyloid polypeptide secretion in neonatal but not adult rat islet cells. Diabetes. 2000;49:1477-84.

33. Sjolander J, Byman E, Kulak K, Nilsson SC, Zhang E, Krus U, Westermark GT, Storm P. King BC, Renstrom E, Blom AM. C4b-binding protein protects beta-cells from islet amyloid polypeptide-induced cytotoxicity. J Biol Chem. 2016;291:21644-55.

34. Zhang S, Liu H, Chuang CL, Li X, Au M, Zhang L, Phillips AR, Scott DW, Cooper GJ. The pathogenic mechanism of diabetes varies with the degree of overexpression and oligomerization of human amylin in the pancreatic islet beta cells. FASEB J. 2014;28:5083-96.

35. Alarcon C, Verchere CB, Rhodes CJ. Translational control of glucose-induced islet amyloid polypeptide production in pancreatic islets. Endocrinology 2012;153:2082-7.

36. Delgado DA, Doherty K, Cheng Q, Kim H, Xu D, Dong H, Grewer C, Qiang W. Distinct membrane disruption pathways are induced by 40 -residue betaamyloid peptides. J Biol Chem. 2016;291:12233-44

37. Sciacca MF, Milardi D, Messina GM, Marletta G, Brender JR, Ramamoorthy A, La Rosa C. Cations as switches of amyloid-mediated membrane disruption mechanisms: calcium and IAPP. Biophys J. 2013;104:173-84.

38. Ho CS, Khadka NK, She F, Cai J, Pan J. Polyglutamine aggregates impair lipid membrane integrity and enhance lipid membrane rigidity. Biochim Biophys Acta. 2016;1858:661-70

39. Cao P, Raleigh DP. In vitro studies of membrane permeability induced by Amyloidogenic polypeptides using large Unilamellar vesicles. Methods Mol Biol. 2016;1345:283-90.

40. Zhang X, St Clair JR, London E, Raleigh DP. Islet amyloid polypeptide membrane interactions: effects of membrane composition. Biochemistry. 2017:56:376-90. 
41. Sciacca MF, Lolicato F, Di Mauro G, Milardi D, D'Urso L, Satriano C, Ramamoorthy A, La Rosa C. The role of cholesterol in driving IAPPmembrane interactions. Biophys J. 2016;111:140-51.

42. Cao P, Abedini A, Wang H, Tu LH, Zhang X, Schmidt AM, Raleigh DP. Islet amyloid polypeptide toxicity and membrane interactions. Proc Natl Acad Sci U S A. 2013;110:19279-84.

43. Gurlo T, Ryazantsev S, Huang CJ, Yeh MW, Reber HA, Hines OJ, O'Brien TD, Glabe CG, Butler PC. Evidence for proteotoxicity in beta cells in type 2 diabetes: toxic islet amyloid polypeptide oligomers form intracellularly in the secretory pathway. Am J Pathol. 2010;176:861-9.

44. Miller-Thomas MM, Sipe AL, Benzinger TL, McConathy J, Connolly S, Schwetye KE. Multimodality review of amyloid-related diseases of the central nervous system. Radiographics. 2016;36:1147-63.

45. Engel MF, Khemtemourian L, Kleijer CC, Meeldijk HJ, Jacobs J, Verkleij AJ, de Kruijf B, Killian JA, Hoppener JW. Membrane damage by human islet amyloid polypeptide through fibril growth at the membrane. Proc Natl Acad Sci U S A. 2008;105:6033-8.

46. Ritzel RA, Meier JJ, Lin CY, Veldhuis JD, Butler PC. Human islet amyloid polypeptide oligomers disrupt cell coupling, induce apoptosis, and impair insulin secretion in isolated human islets. Diabetes. 2007;56:65-71.

47. Westermark GT, Gebre-Medhin S, Steiner DF, Westermark P. Islet amyloid development in a mouse strain lacking endogenous islet amyloid polypeptide (IAPP) but expressing human IAPP. Mol Med. 2000;6:998-1007.

48. Verchere CB, D'Alessio DA, Palmiter RD, Weir GC, Bonner-Weir S, Baskin DG, Kahn SE. Islet amyloid formation associated with hyperglycemia in transgenic mice with pancreatic beta cell expression of human islet amyloid polypeptide. Proc Natl Acad Sci U S A. 1996;93:3492-6.

49. Rochet JC, Lansbury PT Jr. Amyloid fibrillogenesis: themes and variations. Curr Opin Struct Biol. 2000;10:60-8.

50. Groop LC, Saloranta C, Shank M, Bonadonna RC, Ferrannini E, DeFronzo RA. The role of free fatty acid metabolism in the pathogenesis of insulin resistance in obesity and noninsulin-dependent diabetes mellitus. J Clin Endocrinol Metab. 1991;72:96-107.

51. Ohsawa H, Kanatsuka A, Yamaguchi T, Makino H, Yoshida S. Islet amyloid polypeptide inhibits glucose-stimulated insulin secretion from isolated rat pancreatic islets. Biochem Biophys Res Commun. 1989;160:961-7.

52. Poitout V, Hagman D, Stein R, Artner I, Robertson RP, Harmon JS. Regulation of the insulin gene by glucose and fatty acids. J Nutr. 2006;136:873-6.

53. Anguiano M, Nowak RJ, Lansbury PT Jr. Protofibrillar islet amyloid polypeptide permeabilizes synthetic vesicles by a pore-like mechanism that may be relevant to type II diabetes. Biochemistry. 2002;41:11338-43.

54. Demuro A, Mina E, Kayed R, Milton SC, Parker I, Glabe CG. Calcium dysregulation and membrane disruption as a ubiquitous neurotoxic mechanism of soluble amyloid oligomers. J Biol Chem. 2005;280:17294-300.

55. Kagan BL. Amyloidosis and protein folding. Science (New York, NY). 2005; 307:42-3. author reply 42-43

\section{Submit your next manuscript to BioMed Central and we will help you at every step:}

- We accept pre-submission inquiries

- Our selector tool helps you to find the most relevant journal

- We provide round the clock customer support

- Convenient online submission

- Thorough peer review

- Inclusion in PubMed and all major indexing services

- Maximum visibility for your research

Submit your manuscript at www.biomedcentral.com/submit

) Biomed Central 